\title{
Pregnancy Outcomes in Smokeless Tobacco Users Cohort Study in a Tertiary Care Hospital
}

\author{
Ayalur Gopalakrishnan Radhika ${ }^{1}$, Jagdish Kaur ${ }^{2}$, Tusha Sharma ${ }^{3}$, Basu Dev Banerjee ${ }^{3}$, \\ Gita Radhakrishnan', Neelam Bala Vaid1 \\ ${ }^{1}$ Department of Obstetrics and Gynecology, University College of Medical Sciences \& Guru Teg Bahadur \\ Hospital, Delhi, India \\ ${ }^{2}$ Directorate General of CGHS, Ministry of Health and Family Welfare, Government of India, Nirman Bhawan, \\ Delhi, India \\ ${ }^{3}$ Department of Biochemistry, University College of Medical Sciences, Delhi, India \\ Email: ${ }^{*}$ raradhikaag@gmail.com
}

Received 24 March 2014; revised 20 April 2014; accepted 28 April 2014

Copyright $@ 2014$ by authors and Scientific Research Publishing Inc.

This work is licensed under the Creative Commons Attribution International License (CC BY). http://creativecommons.org/licenses/by/4.0/

(c) (i) Open Access

\section{Abstract}

There is a dearth of literature regarding the pregnancy outcomes in antenatal women using smokeless tobacco products (STP). Objective: To compare maternal and neonatal pregnancy outcomes in antenatal women using smokeless tobacco products with those not using tobacco products. Method: Pregnant women attending antenatal clinic at Guru Teg Bahadur hospital, Delhi received brief information about smokeless tobacco products. Antenatal women using STP and matched controls, 92 in each group (total 184) were recruited for the study. After obtaining consent, the urinary cotinine level was measured in both groups at first contact. Antenatal, labour and postpartum events were recorded in both groups. Urinary cotinine levels were again measured at 6 months in the user group. Results: Average age of antenatal women under study was 24.8 yrs and 25.21 yrs in user and non-user groups respectively. More women in the user group were illiterate $(P<0.05)$. Mean urinary cotinine in user and non-users was $44.21+/-20.39$ $\mu \mathrm{g} / \mathrm{ml}$ and $24.37+/-20.14 \mu \mathrm{g} / \mathrm{ml}$ respectively $(\mathrm{p}<0.0001)$. Women using STPs for more than 5 yrs recorded higher urinary cotinine levels. There was no significant difference in urinary cotinine levels with the type of tobacco product consumed. Pregnancy outcomes of 39 women are known. There was no significant difference in antenatal, intra-natal and postpartum complications in the two groups. Neonatal weight difference was 20 gms. Conclusion: Smokeless tobacco products are the most common forms used by women in low and middle income countries. Larger studies are required to understand their effects on pregnancy outcomes.

\footnotetext{
"Corresponding author.
} 


\section{Keywords}

\section{Pregnancy, Smokeless Tobacco Product, Urine Pregnancy Outcome}

\section{Introductions}

Global Adult Tobacco Survey (GATS) 2009-2010 [1] reported that 35\% of adults and 20\% of women in India use tobacco. Smokeless tobacco is used by $21 \%$ of (estimated 163.7 million) adults. Amongst women, $18 \%$ of them use only the smokeless form.

There are a variety of smokeless tobacco products available in India namely, Khaini, Jarda/Zarda, Gutkha, Creamy snuff, Red tooth powder, Tuiber (Tobacco water), paan masala with tobacco, "Mishri”, gul, mawa, etc. Other than oral malignancy, smokeless tobacco is now found to be associated with pancreatic cancer, cardiovascular diseases [2]-[4] and adverse reproductive outcome.

There is a dearth in literature regarding the use of smokeless tobacco in women and pregnancy outcomes. Today, there is robust evidence regarding the reproductive and pregnancy outcomes in women with use of the smoked forms of tobacco but the evidence regarding the harmful effects of smokeless tobacco product use. Research in this area is especially important for the developing nations where prevalence of smokeless tobacco products use especially amongst women is high, greater socio-cultural acceptance is high. This study aims to address this issue and generate evidence related to the use of smokeless tobacco during antenatal period and pregnancy

\section{Objective}

It is to compare maternal and fetal outcomes amongst pregnant users versus non-users of smokeless tobacco products.

\section{Methodology}

This cohort study was conducted at Department of Obstetrics \& Gynecology, Guru Teg Bahadur Hospital (GTB Hospital), Delhi and Department of Biochemistry, University College of Medical Sciences (UCMS), Delhi from March to December 2011.

Selection of participants was done from antenatal clinic at GTB hospital.

Informed consent for inclusion in the study was obtained from all participants.

The women were then interviewed as per a set semi-structured questionnaire. Urine samples of the women (both groups) were then collected for estimation of cotinine levels and tested on the same day. Urine cotinine was measured by ELISA technique (Calbiotech Cotinine ELISA Kit) at recruitment and then, again at 6 months at follow-up to confirm continued use or non-use of STP.

All women received antenatal care as per the set institutional guidelines. Antenatal maternal weight gain during pregnancy, complications like pre-eclampsia, antepartum hemorrhage, fetal growth restriction, operative delivery, neonatal weight and perinatal outcome were recorded for both the groups.

In the period from March to July 2012, a total of 184 pregnant women were recruited for the study. Of these, 92 were using smokeless tobacco, another 92 antenatal women matched for age, BMI, literacy and parity not using any tobacco products, were considered as controls.

Use of tobacco (both smoked and smokeless forms) amongst other family members was also recorded.

Data were entered into SPSS version 18 and analysis included descriptive statistics, independent t-tests and Chi Square. All levels of significance were two-tailed and set at $\mathrm{p}<0.005$.

The study was approved by the Institutional Ethics Committee.

\section{Definitions}

Smokeless tobacco use was defined as at least once a day use for a minimum of three times a week of any of the following locally available smokeless tobacco products e.g., Gul, Zarda, Khaini, gutka, paan masala, etc. 
Quitting Tobacco use was defined as complete non-use of any of the smokeless tobacco product.

\section{Exclusion Criteria}

1) Known smoking habit.

2) Medical disease in the mother.

3) Other addictions e.g., alcohol, any other substance abuse.

4) Pregnancy associated complications at recruitment likely to affect the outcome of the pregnancy e.g., pre-eclampsia, anti-phospholipid antibodies.

\section{Results}

The mean age of pregnant women recruited for study in both groups was $24.86+/-3.91$ years while that in the control group was $25.21+/-3.6$ years. Illiteracy rates amongst STP users were 54\% compared to 33.7\% in nonusers. Mean monthly income in the user group was Rs 4869/- +/- 16.73 while that in the non-user group was Rs 4548/- +/- 15.47. Average money spent by the smokeless tobacco user group was about Rs 30/day. Percentage wise use of smokeless tobacco products and their composition is given in Table 1 . Mean urinary cotinine value in the non-users was $24.37+/-20.14 \mu \mathrm{g} / \mathrm{ml}$, 35\% of these women had urinary cotinine values $0-10 \mu \mathrm{g} / \mathrm{ml}$. Mean urinary cotinine value in the user group was $44.21+/-20.39 \mu \mathrm{g} / \mathrm{ml}, 27 \%$ of these women had urinary cotinine values 50 - $60 \mu \mathrm{g} / \mathrm{ml}$ (Figures 1-3). Women using tobacco for longer durations in years, recorded higher urinary cotinine levels (Table 2). Urinary cotinine levels in daily users were $46.22+/-18.09 \mu \mathrm{g} / \mathrm{ml}$ versus 40.75 $+/-23.75 \mu \mathrm{g} / \mathrm{ml}$ in women using it twice or thrice per week.

Delivery outcome could be known in 39 out of 92 women since some women returned to maternal homes for delivery and also the harvesting season resulted in many families returning to their village. There was no stastical difference in pregnancy outcomes in terms of maternal complications, miscarriage, antepartum hemorrhage, intrauterine growth restriction, birth weight. The mean birth weight in the user group was $2.411+/-0.417 \mathrm{Kg}$ while that in the non-user group was $2.433+/-0.620 \mathrm{Kg}$, i.e., a difference in birth weight of 20 gms (Table 3). When neonatal weights were compared at urinary cotinine cut-off levels at $20 \mu \mathrm{g} / \mathrm{ml}$, the difference in birth weight was 250 gms (Tables 4-5). Though this was not stastically significant, it does have clinical significance since in a country with high incidence of low birth weight; further reduction of 250 gms has an added significance. Comparing two groups with neonatal weight above and below $2.5 \mathrm{~kg}$, there was no significant difference in maternal urinary cotinine values.

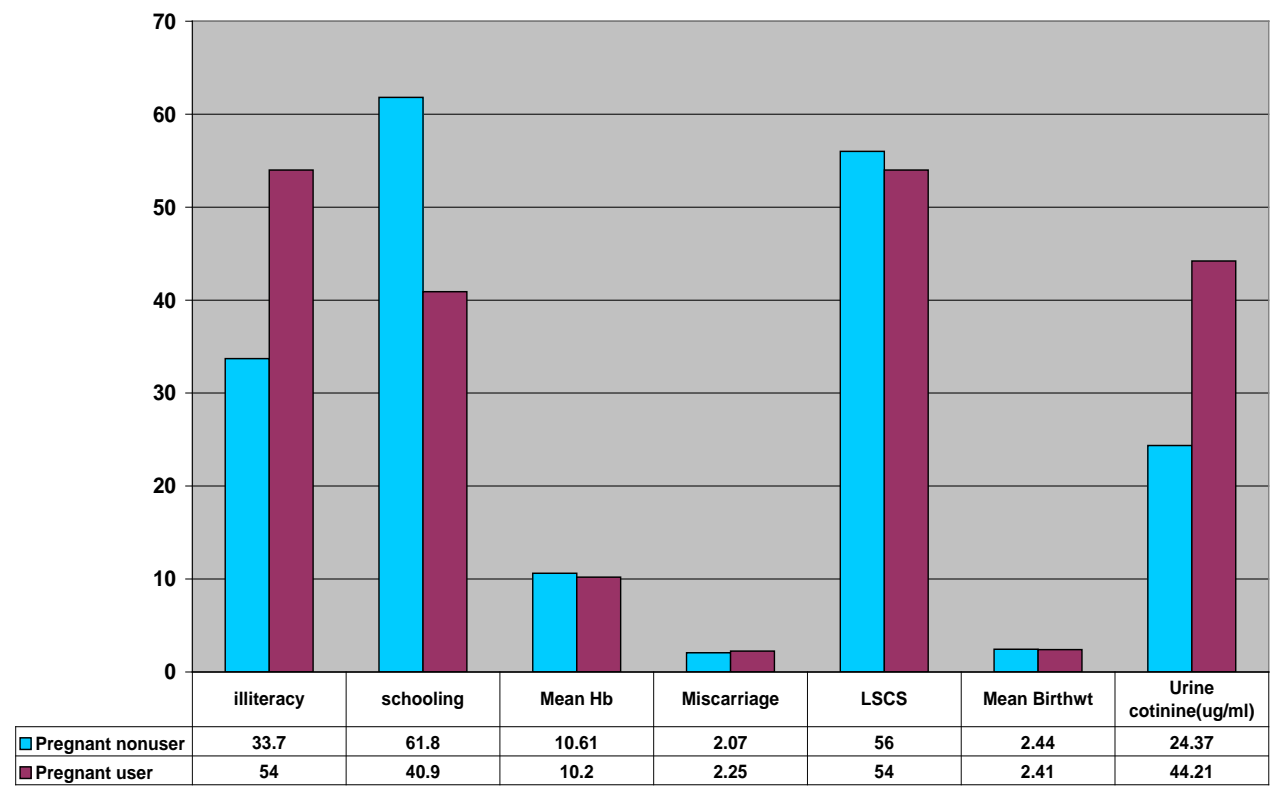

Figure 1. Demographic profile, operative delivery, baby weight and urinary cotinine values in smokeless tobacco user and non-user pregnant women. 


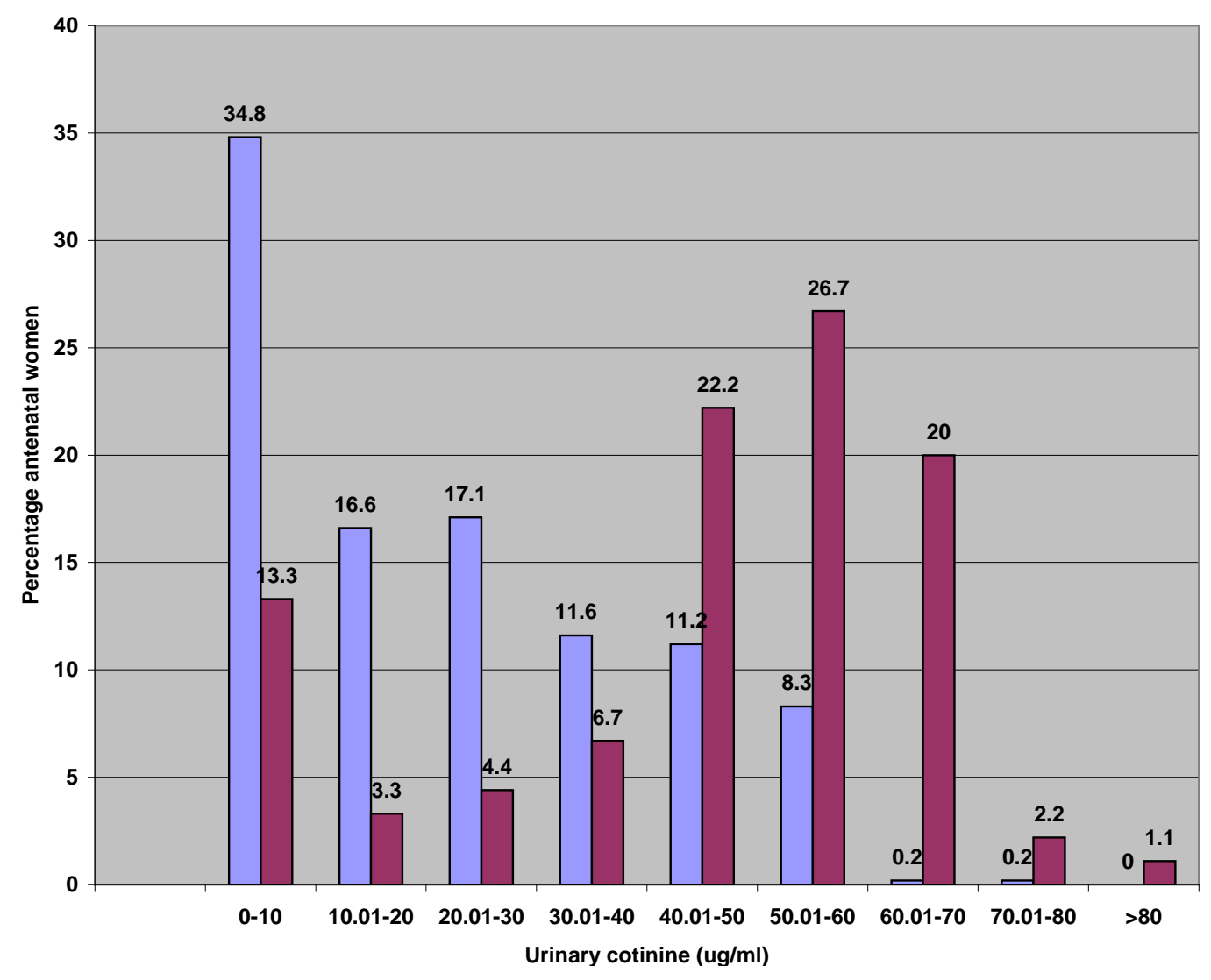

Figure 2. Urinary cotinine values in pregnant user and non-user women.

\section{Antenatal clinic GTB Hospital}

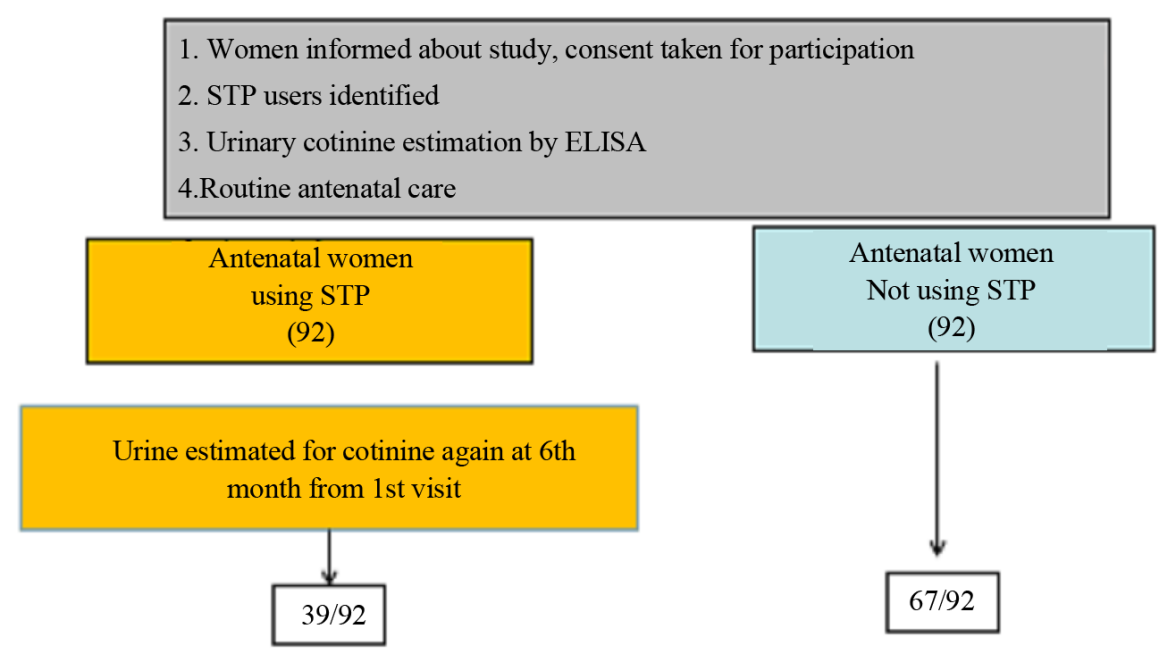

Perinatal outcome recorded in both groups

Figure 3. Methodology flow chart. 
Table 1. Forms of smokeless tobacco products used, percentage of use and description of tobacco products.

\begin{tabular}{|c|c|c|}
\hline Smokeless tobacco product & Description & Women using (\%) \\
\hline Gul & $\begin{array}{l}\text { Made of tobacco powder molasses and other ingredients } \\
\text { Used to clean teeth, applied to gums. }\end{array}$ & 66 \\
\hline Gutkha & Areca nut, catechu, tobacco, lime, saffron and flavouring. & 16 \\
\hline Pan masala & $\begin{array}{c}\text { Made from tobacco, areca nuts, slaked lime and betel nut } \\
\text { condiments. }\end{array}$ & 9.5 \\
\hline Tobacco/Khaini/surti & $\begin{array}{l}\text { Dried or fermented tobacco, slaked lime paste, sometimes } \\
\text { areca nut. }\end{array}$ & 8.4 \\
\hline
\end{tabular}

Table 2. Urinary cotinine levels in relation to duration of use of STP.

\begin{tabular}{ccc}
\hline Addiction habit & Number of women & Mean cotinine $(\boldsymbol{\mu g} / \mathbf{m l})$ \\
\hline$<1$ yr & 30 & 39.08 \\
$1-5$ yrs & 50 & 50.33 \\
$>5$ yrs & 13 & 68.90 \\
\hline
\end{tabular}

Table 3. Mean neonatal birth weight in smokeless to bacco user versus non-user pregnant women.

\begin{tabular}{ccc}
\hline & Pregnant user & Pregnant nonuser \\
\hline Mean Birth wt $(\mathrm{kg})$ & $2.41+/-0.417$ & $2.43+/-0.620$ \\
Urine cotinine $(\mu \mathrm{g} / \mathrm{ml})$ & $44.21+/-20.39$ & $24.37+/-20.14$ \\
\hline
\end{tabular}

Table 4. Mean birth weight in smokeless tobacco user pregnant women using urinary cotinine value cut-off at $20 \mathrm{ng} / \mathrm{ml}$.

\begin{tabular}{cc}
\hline & Mean birth weight (kg) \\
\hline Urinary cotinine $<20 \mathrm{ng} / \mathrm{ml}$ & $2.63+/-0.345$ \\
Urinary cotinine $>20 \mathrm{ng} / \mathrm{ml}$ & $2.38+/-0.421$ \\
\hline
\end{tabular}

\section{Discussion}

Today, the challenge is to contain women's tobacco use in low and middle income countries as women's improving social and economic status has started eroding the traditional barriers to quitting tobacco use.

Studying health effects of the various tobacco products is challenging since different products could have varying levels of nicotine, bioavailability, nicotine delivery, presence of additives, toxin levels, portion size. Moreover, stigma around tobacco use during pregnancy may discourage women from disclosing their tobacco use.

It is well documented that smoking during pregnancy is associated with higher incidence of low birth weight, abruptio placentae, placenta previa and premature rupture of membranes. Studies for the smokeless tobacco use in antenatal mothers and measuring the outcome are few. Assessment of the tobacco use can variously be done by measuring cotinine level, which is a metabolite of nicotine. Cotinine is metabolized in the liver. About $70 \%$ of the nicotine is converted to cotinine in the body. Cotinine has a half life of 15-20 hrs in the body. This is better than nicotine and hence considered a reliable estimate of tobacco use in any form [5]-[6].

In another study of 70 antenatal tobacco users in Jabalpur, birth weight and height of the neonate in the users were significantly reduced (390 gms \& $0.5 \mathrm{~cm}$ respectively) [7]. In a study on the effects of maternal smoking on birth outcomes, multiple linear regression analysis showed exposure of the fetus to nicotine for the entire duration of pregnancy at urinary cotinine levels more than $5 \mu \mathrm{g} / \mathrm{ml}$ resulted in a decrease in birth weight by about 100 gms. For every further increase in cotinine, there was a decrease in the birth weight by $12+/-0.02$ gms [8]. In cohort study of 1217 pregnant women in Mumbai, smokeless tobacco users delivered earlier by 6.2 days ( $\mathrm{p}<$ 0.001 ), the cumulative stillbirth in the smokeless tobacco users was significantly higher than in the non-users (8.9\% vs. 3.1\%) [9]. A statistically significant difference in intrauterine demise rates is also seen in our study- 
Table 5. Socio-demographic profile and pregnancy outcomes.

\begin{tabular}{|c|c|c|}
\hline Variable & Non user (\%) & User (\%) \\
\hline \multicolumn{3}{|l|}{ Age (yrs) } \\
\hline $15-19$ & nil & 3.2 \\
\hline $20-25$ & 63.44 & $59.13 \%$ \\
\hline $26-30$ & 29.03 & 31.18 \\
\hline $31-35$ & 6.45 & 6.45 \\
\hline \multicolumn{3}{|l|}{ Education } \\
\hline \multicolumn{3}{|l|}{ Wife } \\
\hline Illiterate & 29.03 & 56.98 \\
\hline Primary & 16.13 & 15.05 \\
\hline Middle & 3.22 & 5.37 \\
\hline Secondary & 29.03 & 18.27 \\
\hline Higher & 13.98 & 2.15 \\
\hline Graduate & 8.6 & 2.14 \\
\hline \multicolumn{3}{|l|}{ Husband } \\
\hline Illiterate & 18.28 & 35.48 \\
\hline Primary & 7.57 & 13.97 \\
\hline Middle & 5.37 & 5.37 \\
\hline Secondary & 46.24 & 36.55 \\
\hline Higher & 17.2 & 5.37 \\
\hline Graduate & 5.37 & 3.22 \\
\hline Income (Rs) & & 0 \\
\hline $1000-3099$ & 26.88 & 9.67 \\
\hline $3100-5099$ & 53.76 & 69.89 \\
\hline $5100-7099$ & 16.12 & 15.05 \\
\hline$>7100$ & 3.22 & 5.36 \\
\hline \multicolumn{3}{|l|}{ Gravida } \\
\hline G1 & 35.48 & 30.10 \\
\hline G2 & 33.33 & 41.93 \\
\hline G3 & 20.43 & 20.43 \\
\hline G4 & 6.45 & 9.67 \\
\hline$>/=$ G5 & 1.075 & 2.15 \\
\hline $\mathrm{Hb}>11$ gm\% & 39.13 & 21.74 \\
\hline \multicolumn{3}{|l|}{ Complications } \\
\hline Abortion & 1.07 & 2.12 \\
\hline Pre-eclampsia & 19.35 & 2 \\
\hline Intrauterine demise & 1.07 & 6 \\
\hline \multicolumn{3}{|l|}{ Delivery } \\
\hline NVD & 31.11 & 76 \\
\hline LSCS & 56.99 & 18 \\
\hline \multicolumn{3}{|l|}{ Baby weight (kg) } \\
\hline$<1.5$ & 5.37 & 2.08 \\
\hline $1.5-2.49$ & 41.93 & 35.41 \\
\hline$>2.5$ & 43 & 52.6 \\
\hline
\end{tabular}


being higher in the user category $(1.07 \%$ vs. $6 \%, \mathrm{p}<0.05)$. A Cochrane review of 72 studies found that while the smoking cessation interventions had modest effect on quit rates, the impact on infant outcomes were significant [10]-[18].

Expenditure on tobacco products competes with the household expenses on food, health care and other basic needs. The results of the present study highlight the urgent need to implement evidence based interventions to prevent and control tobacco use among pregnant women.

This was an attempt by us to address an important health issue. The limitations of this study include a small sample size, a sizeable numbers were lost to follow-up largely. Traditionally, in India, women go back to their maternal home for delivery.

\section{Conflict of Interest}

The study was funded by World Health Organization; no other financial relationships such as patent or stock ownership, consultancies, speaker's fees, personal, political, intellectual or religious interests with any organization exist. There are no other potential conflicts of interests.

Endorsed by all authors.

\section{Funding}

The study was funded by World Health Organization.

\section{References}

[1] Mackay, J., Eriksen, M. and Shafey, O. (2006) The Tobacco Atlas. 2nd Edition, American Cancer Society, Atlanta.

[2] Shimkhada, R. and Peabody, J.W. (2003) Tobacco Control in India. Bulletin of the World Health Organization, 81, 58-52.

[3] Global Adult Survey 2009-2010, Ministry of Health \& Family Welfare. Government of India.

[4] Bofffeta, P., Hecht, S., Gray, N., Gupta, P. and Straif, K. (2008) Smokeless Tobacco and Cancer. The Lancet Oncology, 9, 667-675. http://dx.doi.org/10.1016/S1470-2045(08)70173-6

[5] Pratinidhi, A., Gandham, S., Shrotri, A., Patil, A. and Pardeshi, S.I. (2010) Use of "Mishri” a Smokeless Form of Tobacco during Pregnancy and Its Perinatal Outcome. Indian Journal of Community Medicine, 5, 14-18.

[6] Zeigler, U.E., Kauczok, J., et al. (2004) Clinical Correlation between the Consumption of Nicotine and Cotinine Concentrations in Urine and Serum by Competitive Enzyme-Linked Immunosorbent Assay. Pharmacology, 72, 254-259. http://dx.doi.org/10.1159/000080381

[7] Verma, R.C., Chansoriya, M. and Kaul, K.K. (1983) Effect of Tobacco Chewing by Mothers on Fetal Outcome. Indian Pediatrics, 20, 105-111.

[8] Wang, X.B., Tager, I.B., Van Vunakis, H., Speizer, F.E. and Hanrahan, J.P. (1997) Maternal Smoking during Pregnancy, Urine Cotinine Concentrations, and Birth Outcomes. A Prospective Cohort Study. International Journal of Epidemiology, 26, 978-988.

[9] Gupta, P.C. and Sreevidya, S. (2004) Smokeless Tobacco Use, Birth Weight and Gestational Age: Population Based Prospective Cohort Study of 1217 Women in Mumbai, India. BMJ, 328, 1538. http://dx.doi.org/10.1136/bmj.38113.687882.EB

[10] Wikstrom, A.-K., Stephansson, O. and Cnattingius, S. (2010) Tobacco Use during Pregnancy and Preeclampsia Risk Effects of Cigarette Smoking and Snuff. Hypertension, 55, 1254-1259. http://dx.doi.org/10.1161/HYPERTENSIONAHA.109.147082

[11] Oncken, C.A., Dietz, P.M., Tong, V.T., Belizan, J.M., Tolosa, J.E., et al. (2010) Prenatal Tobacco Prevention and Cessation Interventions for Women in Low and Middle-Income Countries. Acta Obstetricia et Gynecologica Scandinavica, 89, 442-453. http://dx.doi.org/10.3109/00016341003678450

[12] Fiore, M., Jaen, C., Baker, T., Bailey, W., Benowitz, N., Curry, S., et al. (2008) Treating Tobacco Use and Dependence: 2008 Update. US Department of Health and Human Services, Rockville.

[13] Lumley, J., Chamberlain, C., Dowsell, T., Oliver, S., Oakley, L. and Watson, L. (2009) Interventions for Promoting Tobacco Cessation during Pregnancy. Cochrane Database of Systematic Reviews, 8, CD001055.

[14] Mackay, J. (1996) Women and Tobacco: International Issues. Journal of the American Medical Women's Association, 51, 48-51.

[15] Kramer, M.S. (1987) Determinants of Low Birth Weight: Methodological Assessment and Meta-Analysis. Bulletin of 
the World Health Organization, 65, 663-737.

[16] Krishna, K. (1978) Tobacco Chewing in Pregnancy. British Journal of Obstetrics and Gynaecology, 85, 726-728. http://dx.doi.org/10.1111/j.1471-0528.1978.tb15591.x

[17] Krishnamurthy, S. and Joshi, S. (1993) Gender Differences and Low Birth Weight with Maternal Smokeless Tobacco Use in Pregnancy. Journal of Tropical Pediatrics, 39, 253-254.

[18] Critchley, J.A. and Unal, B. (2003) Health Effects Associated with Smokeless Tobacco: A Systematic Review. Thorax, 58, 435-443. http://dx.doi.org/10.1136/thorax.58.5.435 